\title{
Management of a case of refractory variant angina with benzhexol hydrochloride (trihexyphenidyl hydrochloride)
}

\author{
M JOY, G A HAYWOOD, M M WEBB-PEPLOE \\ From St Peter's Hospital, Chertsey, Surrey; and St Thomas's Hospital, London
}

SUMMARY A patient with severe variant angina that was refractory to conventional treatment became symptom free when she was treated with benzhexol (trihexyphenidyl hydrochloride), a cholinergic blocking agent used in the management of Parkinson's disease. There was a brief psychotic reaction when a large dose was taken and some memory impairment on the maintenance dose. Benzhexol should be used with caution but may prove to be an additional therapeutic agent in the management of severe variant angina.

The syndrome of variant angina, first described by Prinzmetal et al in $1959,{ }^{1}$ is characterised by spontaneous angina pectoris associated with transient ST segment elevation in the electrocardiogram. Typically episodes occur at the same time each day and are often associated with conduction disturbances. There are periods of spontaneous remission. Prinzmetal's hypothesis that the underlying mechanism was coronary artery spasm resulting in transmural ischaemia has now received angiographic support. ${ }^{2}$ It has also become evident that coronary artery spasm is more widely involved in the pathogenesis of angina pectoris ${ }^{34}$ than was formerly believed. Treatment with nitrates and calcium antagonists is usually effective but some patients are refractory to treatment or unable to tolerate these drugs; alternatives such as alpha ${ }_{1}$ blocking agents have recently been evaluated. ${ }^{5}$ Our patient had severe variant angina which was refractory to conventional treatment and proceeded to myocardial infarction.

\section{Case report}

This Lebanese woman aged 37 presented in 1982 with a three month history of central chest pain radiating to the arms and neck which regularly woke her in the early morning and lasted for about 30 minutes. Subsequently the episodes increased in frequency and occurred at rest up to three times in 24 hours and had a repetitive diurnal pattern. The past medical history included mild hypertension, anxiety, and

Requests for reprints to Dr M Joy, St Peter's Hospital, Guildford Road, Chertsey, Surrey KT16 0PZ. palpitation treated with beta blocking agents, and Raynaud's phenomenon. The patient's mother and brother had died aged 52 years and 51 years respectively of myocardial infarction. She smoked occasionally and consumed up to five measures of spirits per day. She denied self medication, in particular with ergot alkaloids.

At initial examination she had a heart rate of 90 beats per minute in sinus rhythm and a blood pressure of $200 / 100 \mathrm{~mm} \mathrm{Hg}$. An apical fourth heart sound and multiple mid-systolic clicks were also noted. The electrocardiogram showed incomplete right bundle branch block and counterclockwise rotation of the heart about its longitudinal axis. A radiograph of the chest was unremarkable apart from some old right basal lung scarring. $M$ mode echocardiography showed no abnormality and Holter monitoring showed asymptomatic periods of $T$ wave inversion associated with sinus tachycardia. Treadmill exercise electrocardiography was terminated by faintness at five minutes of the Bruce protocol. Nonspecific repolarisation changes only were seen. Routine haematology and biochemical assessment showed no abnormality. The atenolol that she had been receiving was replaced by nifedepine which at $>30 \mathrm{mg} /$ day seemed to worsen symptoms whereas 5 $\mathrm{mg}$ three times a day was beneficial. Beta blocking agents with both high and low intrinsic sympathomimetic activity were not beneficial. Nitrates administered sublingually or as a spray consistently aborted the attacks of angina but neither dinitrates nor mononitrates could be tolerated because they produced headache, and topical nitrates caused rashes. 
In August 1982, six months after presentation the patient was admitted to hospital after a prolonged episode of pain. Serum aspartate transaminase and lactate dehydrogenase concentrations were slightly increased but technetium-99m pyrophosphate scanning did not show evidence of a myocardial infarction. Subsequent coronary angiography showed only a $40 \%$ stenosis. of the right coronary artery at the catheter tip, which persisted despite sublingual glyceryl trinitrate, and $30 \%$ stenosis of the coronary artery at the origin of the right ventricular branch. There was also a $30 \%$ stenosis at the origin of the left anterior descending coronary artery. Despite modification of treatment, including a trial of verapamil, the symptoms became worse and angina on exercise developed and resulted in further hospital admissions (in April 1983 and July 1983). During the admission in July acute anterior myocardial infarction was diagnosed on the basis of electrocardiography (Fig. 1) and a concomitant increase of concentrations of the serum enzymes. Subsequently a technetium- $99 \mathrm{~m}$ multiple gated acquisition study of the left ventricle showed an ejection fraction of 0.68 with good and uniform contraction. Myocardial scintigraphy with thallium-201 showed evidence of anterior myocardial infarction with exercise induced ischaemia in the high lateral and lower septal walls. Recording of a simultaneous 12 lead exercise electrocardiogram was limited by pain, and ST segment elevation and widening of the QRS complexes were seen (Fig. 2). Similar changes were seen on one occasion during an episode of early morning pain on 24 hour ambulatory monitoring. In view of continuing uncontrolled pain at rest and on exercise, a second coronary angiogram was performed in September 1983 but no appreciable change was seen in the arterial lesions.

\section{Subsequent management}

During the next two months her symptoms became worse and, since parasympathetic activation may be one mechanism in variant angina, ${ }^{6}$ we decided to treat her with the anticholinergic drug benzhexol (trihexyphenidyl hydrochloride) which is commonly used in the management of Parkinson's disease. The initial dose of $2 \mathrm{mg}$ three times a day was increased slowly to $4 \mathrm{mg}$ four times a day. In the three months that the patient was on benzhexol she had only one episode of angina. With her agreement we then

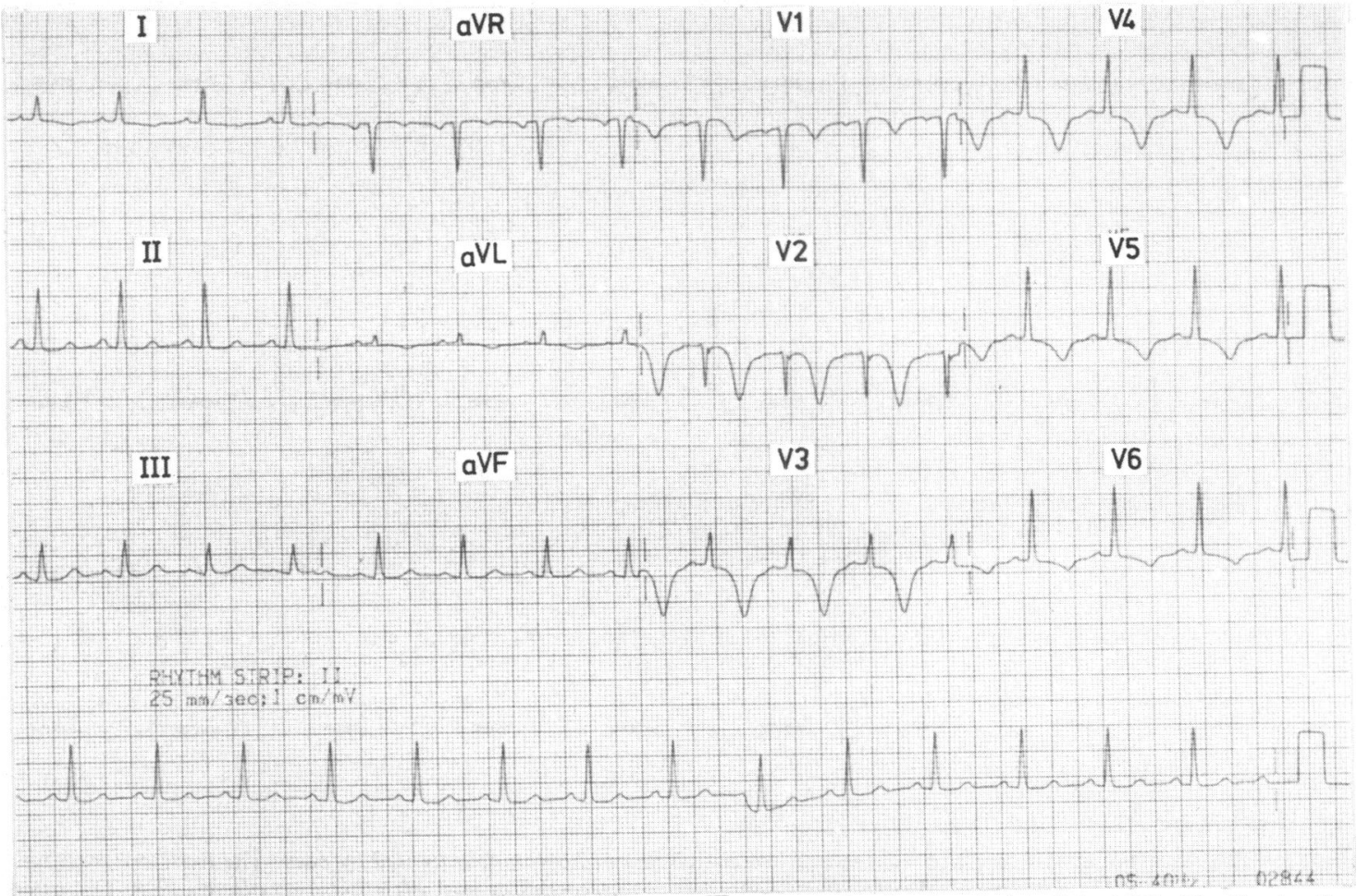

Fig. 1 Twelve lead electrocardiogram recorded when the patient was admitted to hospital in fuly 1983. The Pardee T wave inversion subsequently resolved. 
reduced the dose of benzhexol by $2 \mathrm{mg}$ every two days. When benzhexol was stopped completely the patient reported attacks of angina both at rest and on exercise which were associated with vomiting. She asked to restart the drug and was instructed to increase the dose by $2 \mathrm{mg}$ every two days but she misunderstood these instructions and took the full dose of $4 \mathrm{mg}$ four times a day. This precipitated a brief psychotic reaction with excitability and paranoia which resolved when the dose was reduced. Apart from the attacks of pain that she experienced during the period of withdrawal, the patient has had only four episodes of angina in the nine months since treatment with benzhexol was started, and two of these were associated with emotional upsets. She reports increased feelings of wellbeing and impairment of memory on the full dose-both are known side effects of benzhexol. She continues to take $4 \mathrm{mg}$ of benzhexol three times a day.

\section{Discussion}

The use of benzhexol is a novel approach to treating variant angina. Yasue reported that atropine (a parasympathetic blocking agent) at a dose of 1.2 to $2.0 \mathrm{mg}$ at night suppressed attacks of pain in about $80 \%$ of cases. $^{7}$ He nevertheless commented that atropine was not likely to have any advantages over the newly developed calcium antagonists. Our patient responded well to benzhexol, after treatment with a calcium antagonist had been unsuccessful. The mechanisms involved in variant angina when the coronary arteries appear to be nearly normal by angiography and the condition is refractory to calcium channel blocking agents are unknown. In vitro the contractile response of human coronary arteries to various physiological agents, including acetylcholine, is biphasic. ${ }^{8}$ The response to acetylcholine is dependent on a fast phase of contraction mediated
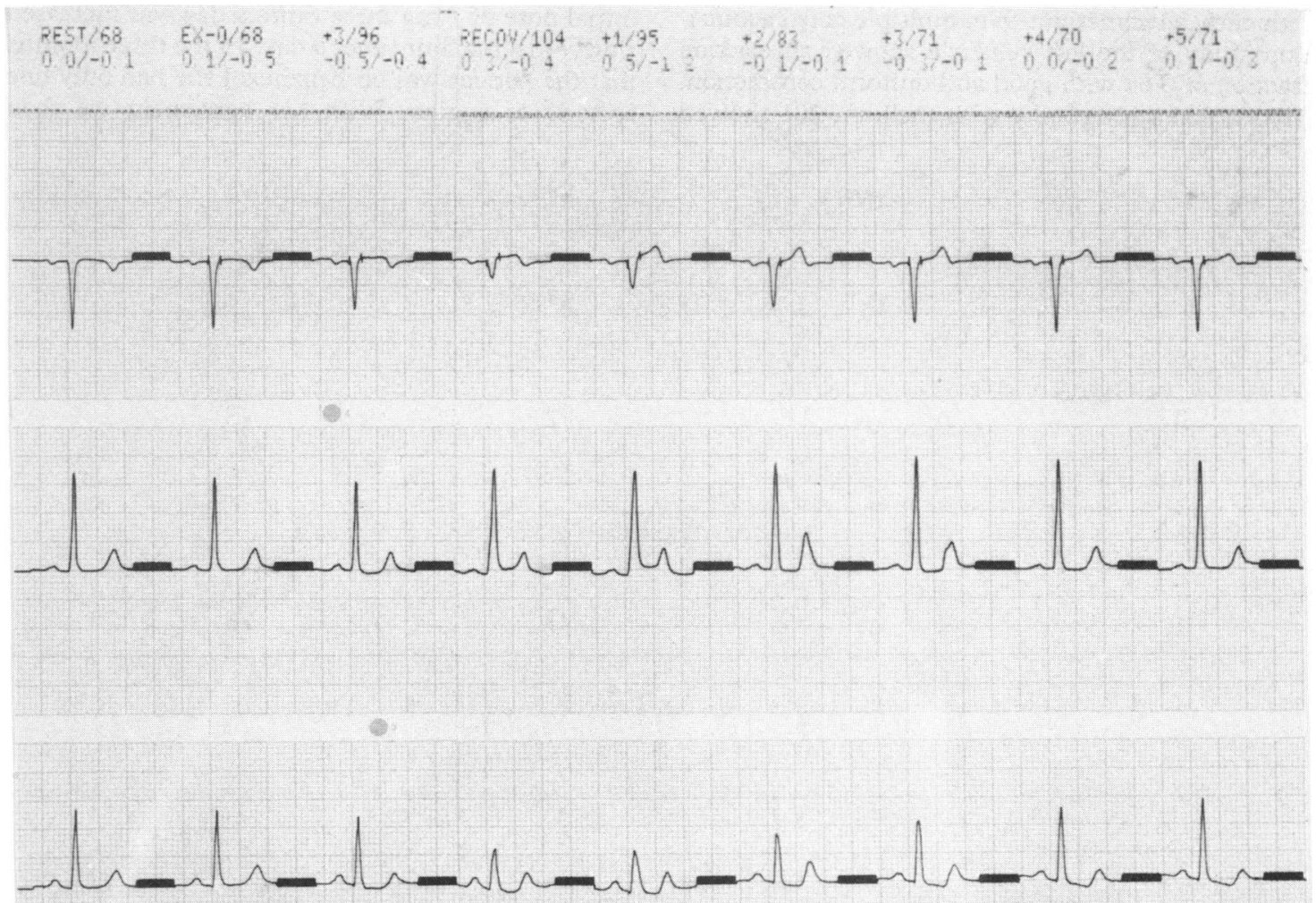

Fig. 2 The recording of this computer synthesised exercise electrocardiogram was limited by pain. The leads are from top Fig. 2 The recording of this computer synthesised exercise electrocardiogram was limited by pain. The leads a each three minutes of exercise, at maximum exercise, and for each minute for ten minutes of recovery. Note the ST segment elevation in V5. 
by intracellular calcium release and a slow phase related to calcium influx via cell membrane channels. Calcium antagonists block only the cell membrane channels, thus in patients with refractory variant angina the fast phase of contraction may be dominant. This could explain the apparent success of parasympathetic blockade in the management of this patient when treatment with slow channel calcium antagonists was unsuccessful. It also emphasises the involvement of the parasympathetic nervous system in variant angina.

\section{References}

1 Prinzmetal M, Kennamer R, Merliss R, Wada T, Bor N. Angina pectoris. I. A variant form of angina pectoris: preliminary report. $A m \mathcal{F}$ Med 1959; 27: 375-88.
2 Oliva PB, Potts DE, Pluss RG. Coronary arterial spasm in Prinzmetal angina. Documentation by coronary arteriography. $N$ Engl f Med 1973; 288: 745-51.

3 Braunwald E. Coronary artery spasm. $\mathcal{F} A M A$ 1981; 246: 1957-9.

4 Maseri A, Severi S, De Nes M, et al. "Variant" angina: one aspect of a continuous spectrum of vasospastic myocardial ischemia. Am $\mathcal{F}$ Cardiol 1978; 42: 1019-35.

5 Tzivoni D, Keren A, Benhorin J, Gottlieb S, Atlas D, Stern $S$. Prazosin therapy for refractory variant angina. Am Heart f 1983; 105: 262-6.

6 Yasue H, Touyama M, Shimamoto M, Kato H, Tanaka $\mathrm{S}$, Akiyama F. Role of autonomic nervous system in the pathogenesis of Prinzmetal's variant form of angina. Circulation 1974; 50: 534-9.

7 Yasue H. Pathophysiology and treatment of coronary arterial spasm. Chest 1980; 78: 216-23.

8 Ginsberg R, Bristow MR, Harrison DC, Stinson EB. Studies with isolated human coronary arteries. Chest 1980; 78: 180-6. 